\title{
News Brief: The Starfish Story of the UST Hospital Outreach and Indigency Programs Wins Corporate Social Responsibility of the Year Award from Healthcare Asia
}

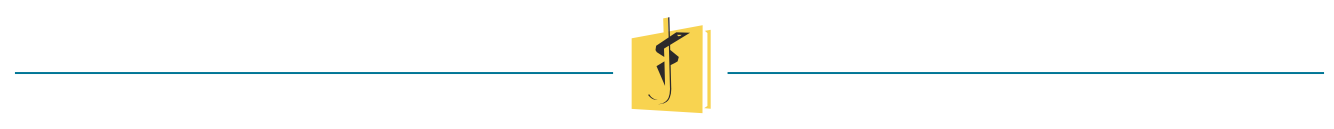

\section{Marcellus Francis I. Ramirez, MD}

One patient. One starfish....at a time...thrown back to the sea.[1]

This was the inspirational "battle cry" of the University of Santo Tomas Hospital (USTH) Chief Executive Officer, Fr. Manuel Roux, during the report on the outcomes of the Outreach and Indigency Programs of the USTH.

In 2016, in celebration of its $70^{\text {th }}$ anniversary, the USTH launched the Hospital Outreach and Patient Education program and provided free services in the form of free vaccinations, free diagnostic and ancillary tests, and patient health screening for indigent patients of the community. Various lay fora providing patient education were also held. With its success and the growing demand for more programs of the same nature, the USTH management planned out a more comprehensive program that will provide totally free interventions and treatments for patients. Various non-government agencies and companies and private individuals gave financial donations to jumpstart the program. Fueled by the generosity of these companies which supported the program, other private physicians also shelled out money for certain programs and in December 2017, during the hospital Christmas celebration, the USTH Outreach and Indigency Program was formally launched.
What succeeded was an avalanche of ongoing projects from December 2017 with more than 2,000 patients being benefited from free medical and surgical interventions across different multidisciplinary settings. This included breast cancer surgeries, thyroidectomies, hernia repair, gynecologic surgeries, and hand surgeries. A total of 71 patients underwent free coronary angiographies, angioplasties with coronary stenting, and permanent pacemaker and defibrillator implantation, done in 7 batches. A selected number of beneficiaries underwent free hemodialysis access surgeries (arteriovenous fistula creation). The programs also included free clinics and wellness programs for pediatric and adult patients.

Alluding to the little boy throwing one starfish at a time back to the ocean in the "Starfish Story" (original story "The Star Thrower" by Loren Eiseley 1907-1977),[1] Fr. Roux declared, "It may not be a change in the world as we know it, but it makes a difference in the world of every patient who benefited from the program... These patients are given another chance to live, to hope and to be a fruitful member of the community."

On May 23, 2019, the UST Hospital was awarded by Healthcare Asia as the Corporate Social Responsibility of the Year-Philippines 
for its Outreach and Indigency Programs dubbed "A Starfish Story", at the Healthcare Asia Awards 2019 ceremonies in Conrad Centennial, Singapore. The Awards Night "aimed to honor hospitals and clinics that rise above industry challenges and recognize initiatives that maximized the lucrative opportunities in the healthcare market."

This year's nominations were judged by a panel consisting of Abhay Bangi, Partner, Life Sciences \& Healthcare Lead, Ernst \& Young; Dr. Loke Wait Chiong, Executive Director, Healthcare Sector Leader, Deloitte; Dr. Zubin Daruwalla, Director, SEAC Health Industries Leader, PwC; Chin Chee Choon, Advisory Leader of Nexia TS, and; Willy Leow, Partner, Risk Advisory Services, BDO LLP.

Indeed, the Outreach and Indigency Programs, with its medical and surgical missions, will not be able to benefit and reach out to a majority of the population, but each surgery done whether major or minor, each cardiac intervention completed, each eye refracted, each person screened, examined, and treated through the wellness programs, is a starfish thrown back to the sea. And each effort in the Indigency Program has simply made a difference in their lives.

\section{REFERENCE:}

1. Eiseley L. The immense journey. New York: Vintage Books; 2013.

Open Access This article is licensed under a
Creative Commons Attribution 4.0 International
License, which permits use, sharing, adaptation, distribution
and reproduction in any medium or format, as long as you give
appropriate credit to the original author(s) and the source, pro-
vide a link to the Creative Commons license, and indicate if
changes were made. The images or other third party material in
this article are included in the article's Creative Commons li-
cense, unless indicated otherwise in a credit line to the material.
If material is not included in the article's Creative Commons li-
cense and your intended use is not permitted by statutory regu-
lation or exceeds the permitted use, you will need to obtain
permission directly from the copyright holder. To view a copy of
this license, visit http://creativecommons.org/licenses/
by/4.0/.

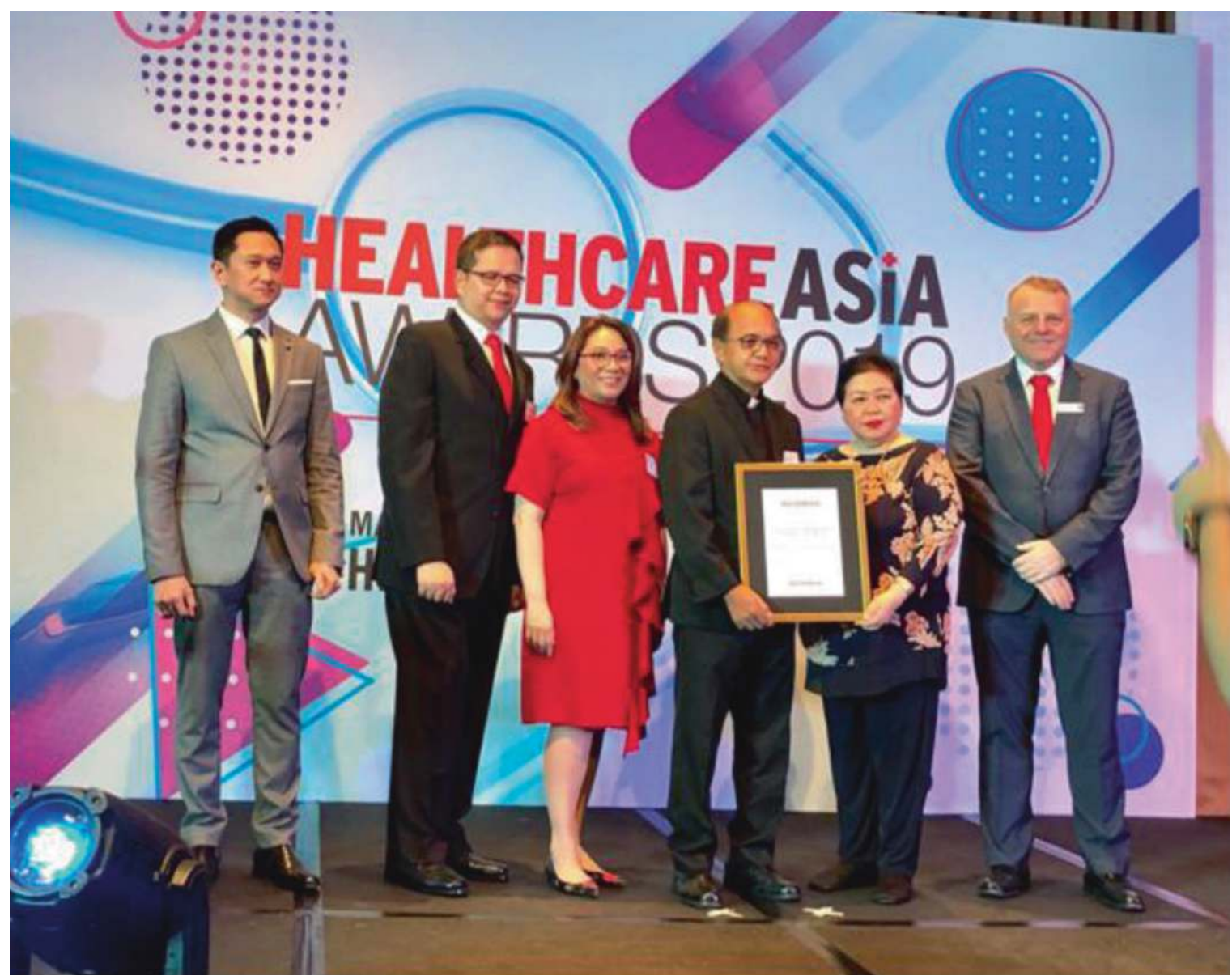

Left to Right Dr. Gerald Alcid, Chairman of the USTH Department of Surgery, Dr. Marcellus Francis Ramirez, Acting Medical Director, Dr. Aileen Cynthia De Lara, Chair of Department of Medical Education and Research; Rev. Fr. Manuel Roux, OP, USTH Chief Executive Officer, Ms. Isidora Lee, Director for Finance and Administration, and Tim Charlton, Healthcare Asia Editor-in-Chief 